\title{
Polymerase chain reaction- and RNA hybridization-based method for the investigation of deep-seated candidiasis
}

Peter R Couroux MD FRCPC, Zafar Hussain MD FRCPC, Frank Rutledge MD FRCPC, Robert Lannigan MDCM FRCPC, Edward D Ralph MD FRCPC, Barbara Nancekivell MLT, Thomas W Austin MD FRCPC

PR Couroux, Z Hussain, F Rutledge, et al. Polymerase chain reaction- and RNA hybridization-based method for the investigation of deep-seated candidiasis. Can J Infect Dis 1997;8(6):329-334.

OBJECTIVE: To determine the usefulness of a polymerase chain reaction (PCR) and RNA hybridization method for the diagnosis of invasive candidiasis and to compare its sensitivity with blood cultures.

DESIGN: Blood cultures and a blood sample for PCR were taken from patients with suspected invasive candidiasis. A 105 base pair conserved segment within the rDNA of Candida species was amplified. The amplicon was detected by hybridization and gel electrophoresis.

SETTING: Intensive care units of two tertiary care hospitals.

PATIENTS: One hundred and eighteen patients 16 years of age or older with four more risk factors for invasive candidiasis were enrolled. Present or recent past treatment with broad spectrum antibiotics, cancer chemotherapy, immunosuppressive drugs, granulocytopenia or granulocytosis, intravascular catheterization, tracheal intubation, recent abdominal surgery and parenteral nutrition were considered risk factors.

RESULTS: Forty-three patients had invasive candidiasis. PCR detected infections in 28 and 26 patients (sensitivity $65.1 \%$ and $60.4 \%$ ) by hybridization and gel electrophoresis, respectively. The sensitivity of blood cultures was $58.1 \%$. Of 25 patients with positive blood cultures, 17 were positive by PCR with the hybridization method. Eleven patients with invasive candidiasis had negative blood cultures but were positive by PCR.

CONCLUSION: PCR, especially with a hybridization detection method, is more sensitive than blood culture for invasive candidiasis and may facilitate the diagnosis of nonfungemic disease.

Key Words: Candidiasis, DNA amplification, Polymerase chain reaction

\section{Méthode d'investigation diagnostique de la candidose profonde par amplification génique et d'hybridation de I'ARN}

OBJECTIF : Déterminer l'utilité de l'amplification génique et de l'hybridation de l'ARN comme méthodes diagnostiques appliquées à la candidose invasive et comparaison de sa sensibilité avec celle des hémocultures.

MODĖLE : Des hémocultures et un échantillon sanguin pour amplification génique ont été prélevés chez des patients souffrant d'une candidose invasive soupçonnée. Un segment conservé de 105 paires de bases à l'intérieur de l'ADNr de

Department of Microbiology and Critical Care and Trauma Unit, Victoria Hospital; Department of Microbiology and Immunology and Department of Internal Medicine and Infectious Diseases, The University of Western Ontario, London Ontario

Correspondence and reprints: Dr Z Hussain, Department of Microbiology and Infection Control, Room 307 C, Westminster Tower, London Health Sciences Centre, 800 Commissioners Road East, London, Ontario N6A 4G5. Telephone 519-685-8149, fax 519-685-8203, e-mail zafar.hussain@lhsc.on.ca

Received for publication November 1, 1996. Accepted March 13, 1997 
souches de Candida a été amplifié. L’amplicon a été décelé par hybridation et électrophorèse sur gel. CONTEXTE : Unité de soins intensifs de deux hôpitaux de soins tertiaires.

PATIENTS : Cent dix-huit patients âgés de 16 ans ou plus et présentant quatre facteurs de risque supplémentaires à l'égard de la candidose invasive ont été inscrits. On a considéré parmi les facteurs de risque un traitement présent ou récent au moyen d'antibiotiques à large spectre, de chimiothérapies contre le cancer, de médicaments immunosuppresseurs, la granulocytopénie ou la granulocytose, les cathétérismes intravasculaires, l'intubation trachéale, une chirurgie abdominale récente et l'alimentation parentérale.

RÉSULTATS : Quarante-trois patients présentaient une candidose invasive. L'amplification génique a servi à dépister les infections chez 28 et 26 patients (sensibilité $65,1 \%$ et 60,4\%) par hybridation et électrophorèse sur gel respectivement. La sensibilité des hémocultures a été de $58,1 \%$. Parmi les 25 patients présentant une hémoculture positive, 17 se sont révélés positifs au moyen du test d'amplification génique avec hybridation, 11 patients présentant une candidose invasive avaient des hémocultures négatives, mais des résultats positifs à l'amplification génique.

CONCLUSION : L'amplification génique, surtout avec méthode de dépistage par hybridation est plus sensible que l'hémoculture pour déceler la candidose invasive et pourrait faciliter le diagnostic de la maladie non fongémique.

$\mathbf{I}^{\mathrm{n}}$ nvasive candidiasis is difficult to diagnose and is associated with substantial morbidity and mortality. Methods of diagnosis include blood cultures, imaging techniques (computed tomography scanning and magnetic resonance imaging) and tissue biopsy. These methods lack sensitivity and are often positive only in advanced stages of infection. Only $73 \%$ of patients with autopsy-proven disseminated candidiasis had positive blood cultures.

Often recovery of yeast by blood culture is slow, with the mean interval to recovery from the day of collection ranging from 3.4 to 5.0 days, depending on the blood culture method used $(1,2)$. Newer diagnostic techniques - including detection of mannans, a candida cell-wall antigen (3), D-arabinitol, a candida metabolite (4), and candida enolase, a cytoplasmic antigen (5) - have been used but are essentially research tools.

Clearly, a rapid sensitive and specific method for the diagnosis of invasive candidiasis is needed. We describe a polymerase chain reaction (PCR)-based method with an enzyme immunoassay (EIA) for the detection of the amplified product that appears to be suitable for this purpose.

\section{PATIENTS AND METHODS}

Study population: All patients with a variety of medical diseases and surgical problems older than 16 years of age and who were patients of the Critical Care Trauma Centre of the London Health Sciences Centre, Victoria Campus or the Intensive Care Unit of the University Campus, London, Ontario were included in the study. Febrile patients (temperature greater than $38.5^{\circ} \mathrm{C}$ ) at risk for invasive candidiasis were enrolled in this study. Those considered at high risk had four or more of the following risk factors: present or recent past treatment with broad spectrum antibiotics and/or chemotherapy; granulocytopenia (less than $1.5 \times 10^{9} / \mathrm{L}$ ) or granulocytosis (greater than $10 \times 10^{9} / \mathrm{L}$ ); immunosuppressive therapy (corticosteroid, azathioprine or cyclosporine); intravascular catheterization; tracheal intubation; recent abdominal surgery; or centrally administered parenteral nutrition.

Invasive candidiasis was defined as a positive culture for Candida species in blood, deep tissue or normally sterile body fluids excluding urine. Patients, with negative candida cultures but who were thought to have invasive candidiasis and who improved with empiric antifungal but not with antibacte- rial treatment, were designated as having possible invasive candidiasis. Colonization was defined as the isolation of candida from mucosal surfaces or a catheter specimen of urine. A positive blood culture for Candida species and/or the growth of a yeast from a deep tissue or normally sterile body fluid, excluding urine, was defined as invasive candidiasis. In the presence of both or either condition a patient was considered to have invasive candidiasis.

Patients were enrolled and treated by three of the authors who also collected patient data and monitored the outcome of antifungal therapy. The study was approved by the ethical review committees of the participating institutes and the University of Western Ontario, London, Ontario.

Microbiological monitoring: Specimens of blood, sterile body fluids, bronchial lavage and brushing, mucosal surfaces and urine for bacterial culture were obtained as clinically indicated. Specimens for blood cultures, fungal cultures and PCR were collected when invasive candidiasis was suspected. Specimens were processed using standard techniques as previously described (6). For blood cultures the nonradiometric Bactec (Becton Dickinson Diagnostic Instrument Systems, Maryland) method was used at the Victoria campus. Blood was collected in Bactec Plus Aerobic/F and Bactec Plus Anaerobic/F vials. Each vial contains 8 to $10 \mathrm{~mL}$ of blood. The vials were incubated and read using the Bactec 9240 system. At the University campus, FAN aerobic and anaerobic bottles (Organon Teknika, North Carolina)were used to collect blood, and the bottles were incubated at $35^{\circ} \mathrm{C}$ for five days in the BactiAlert (Organon Teknika) module. Tips of intravascular catheters were cultured semiquantitatively as previously described (7). All specimens were observed for the growth of yeast. Yeasts were identified with the use of germ tube, cornmeal agar and the API-20C system (Analytab, New York).

Processing of specimens for PCR: Blood was collected in EDTA-containing tubes and submitted to the Microbiology Laboratory. Once a patient was recruited in this study, clinical data were collected and patients followed by one of the investigators.

Specimens were processed in the PCR laboratory without the knowledge of other microbiological results, therapy and outcome. PCR results were not used in clinical decision-making and were not available to the attending physician during the course of treatment, except in one case of candidal menin- 
gitis. In this case, PCR results were given to the attending physician after one of the cerebrospinal fluid (CSF) specimens grew Candida albicans, and therapy was initiated. This patient, however, was not included in the calculation of sensitivity.

DNA extraction: Approximately $3 \mathrm{~mL}$ of each blood specimen was mixed with $35 \mathrm{~mL}$ of azide free buffered electrolyte solution, Isoton II (Coulter Electronics of Canada Ltd) and 13 drops of Zap-o-Globin7 (Coulter Electronics of Canada Ltd). After centrifugation at $10,000 \mathrm{~g}$ for 30 mins, the supernatant was decanted completely. To the pellet, $1 \mathrm{~mL}$ of nuclear lysis buffer (0.01 M TRIS, 0.4 M sodium chloride, 0.002 M EDTA, pH 8.2) containing $7.5 \mathrm{mg} / \mathrm{mL}$ zymolyase, was added, and the tube was briefly vortexed. After the addition of 100 L of $20 \%$ sodium dodecysulphate (SDS), the specimen was kept in a shaker incubator at $37^{\circ} \mathrm{C}$ until the pellet was completely digested ( 3 to $5 \mathrm{~h}$ ). Subsequent to overnight proteinase $\mathrm{K}$ (final concentration $1 \mathrm{mg} / \mathrm{mL}$ ) (Sigma, Missouri) treatment at $37^{\circ} \mathrm{C}$, the specimen was boiled for 7 mins. DNA was extracted with an equal amount of TRIS-buffered phenol:chloroform:isoamyl alcohol (25:24:1) (Sigma, Missouri) twice and once with chloroform:isoamyl alcohol (24:1). DNA was precipitated with concentrated isopropyl alcohol and $0.2 \mathrm{M}$ sodium chloride according to previously described techniques (8) and resuspended in 60 L sterile water.

CSFs and body fluids other than blood were processed in a similar fashion, but with a slight modification. After centrifugation, the supernatant was discarded, and the pellet was digested with nuclear lysis buffer, zymolyase and SDS without the prior treatment with Isoton II and Zap-o-Globin.

Amplification: The primers, PCON-1 (5 -AGT TTC GCG TAT GGT CC) and PCON-2 (5 -GTT GCG GCC ATA TCT AGC), amplify a highly conserved sequence within the rDNA region of yeasts. The primers have been shown to produce a 105 base pair amplicon from six Candida species and to detect $15 \pm 5$ colony forming units (CFU) of $C$ albicans (9). Oligonulceotides were synthesized on the Pharamacia Gene Assembler Plus by the Medical Research Council Group in Fetal and Neonatal Health and Development Core Facility. In this study, the PCON-1 used was biotinylated.

Amplification was carried out in a volume of 60 L containing 20 pmol of each primer, standard amounts of Gene-Amp reagents (Perkin-Elmer-Cetus), $2.5 \mathrm{mM}$ of magnesium chloride, $10 \%$ glycerol and $25 \mathrm{~mL}$ of template. The AmpliWax (Perkin-Elmer-Cetus)-mediated hot start method was used for amplification to avoid mispriming in the presence of human background DNA (10). Amplification was performed in a programable thermocycler GeneAmp PCR system 9600 (PerkinElmer-Cetus) with 5 mins of denaturation at $95^{\circ} \mathrm{C}$ followed by 40 cycles consisting of $25 \mathrm{~s}$ of denaturation at $95^{\circ} \mathrm{C}, 40 \mathrm{~s}$ of annealing at $55^{\circ} \mathrm{C}$ and $50 \mathrm{~s}$ of extension at $72^{\circ} \mathrm{C}$.

Detection of amplified product: Gel electrophoresis was carried out through a $9 \%$ polyacrylamide gel containing ethidium bromide. Positive and negative controls were included with each run of amplification and electrophoresis. Positive controls consisted of purified $C$ albicans DNA and DNA extracted from $3 \mathrm{~mL}$ blood spiked with $10 \mathrm{CFU}$ of $C$ albicans. Negative

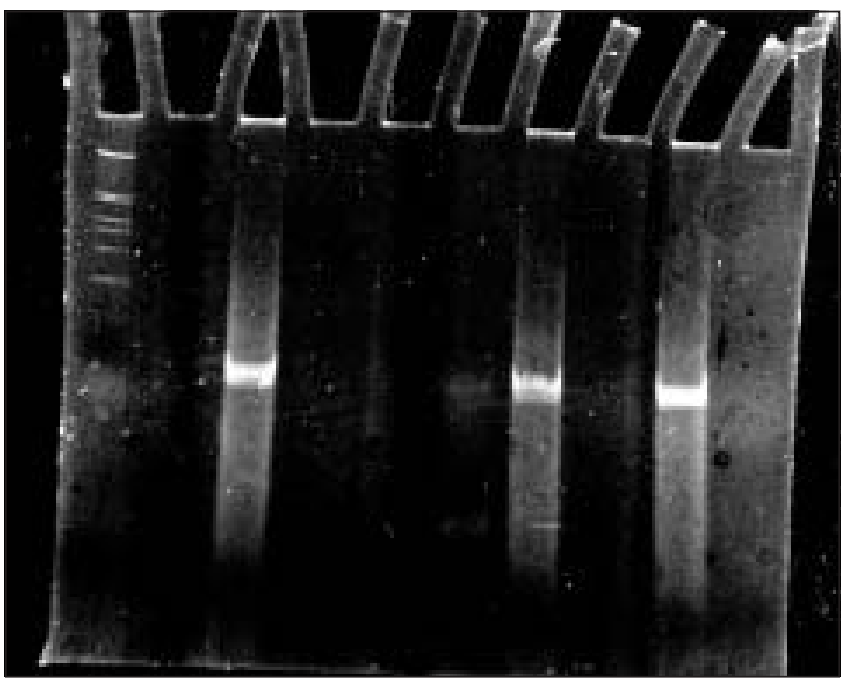

Figure 1) Ethidium bromide-stained polyacrylamide gel of DNA markers (lane 1), polymerase master mix with water (negative control, lane 2) and amplification products of purified DNA of Candida albicans (lane 3), negative control of amplification (amplification without template) (lane 4), unspiked blood (lane 5), blood spiked with 10 colony forming units of $\mathrm{C}$ albicans (lane 6), patients (lanes 7 to 10)

controls included DNA extracted from unspiked blood and PCR buffer (Figure 1). To confirm the specificity of bands, an EIA was also performed with an RNA probe complementary to the upstream primer (PCON-1).

Synthesis of RNA probe: First, a PCon-2 was synthesised with the T7 RNA polymerase promoter attached at the 5 end. Using PCON-1 and PCON-2 with a T7 polymerase promoter, and $20 \mu \mathrm{g}$ of purified $C$ albicans genome as the template, amplification was carried out under the conditions as described above. After extraction and precipitation, the DNA (amplicon) was reconstituted in sterile water, and its concentration was determined.

The RNA probe was transcribed from the purified amplicon, using the RiboMax Large Scale RNA Production System (Promega Corporation, Wisconsin), according to the manufacturer's instruction. The DNA template was removed by digestion with RQ1 RNase free DNase (Promega). Subsequent to phenol:chloroform:isoamyl alcohol extraction and ethanol precipitation, RNA was reconstituted in diethylpyrocarbonate-treated RNA stabilizing buffer (10 mM Tris, pH 7.0, 15 mM sodium chloride, $0.2 \%$ SDS) to a concentration of $200 \mu \mathrm{g} / \mathrm{mL}$. EIA: EIA detection was performed according to the instructions of the Diegene Sharp Signal System (Diegene Diagnostics, Maryland). Briefly, sample PCR DNA was denatured and hybridized with the RNA probe. Hybridized product was captured in a streptavidin-coated microplate well. After washing, alkaline phosphatase conjugated anti-RNA:DNA antibodies were added to the wells. After 30 mins incubation on a microplate rotary shaker, the content of the wells was removed and the substrate para-nitrophenylphenol was added. Microplate was incubated at $37^{\circ} \mathrm{C}$ for $24 \mathrm{~h}$. Absorbance was determined on an EIA reader at $405 \mathrm{~nm}$ with automatic blank correction. The cutoffs for a positive result were determined according to the 
TABLE 1

Detection of yeast by blood cultures and enzyme immunoassay-polymerase chain reaction (PCR) (gel electrophoresis) in patients with invasive candidiasis, and sensitivity and specificity of test methods

\begin{tabular}{lcccccc}
\hline & \multicolumn{2}{c}{ Patients with positive } & \multicolumn{2}{c}{ Sensitivity (\%) } & \multicolumn{2}{c}{ Predictive value (PCR) } \\
Group & Blood culture & PCR & Blood culture & PCR (blood) & Positive & Negative \\
\hline Candidemia $(n=25)$ & 25 & $17(15)$ & & & & \\
Possible candidiasis $(n=18)$ & 0 & $11(11)$ & & & & \\
Total $(\mathrm{n}=43)$ & 25 & $28(26)$ & 58.1 & $65.1(60.4)$ & $96.6(96.2)$ & - \\
Noncandidiasis $(\mathrm{n}=75)$ & 0 & 1 & - & - & $91.0(89.0)$ \\
\hline
\end{tabular}

Results of gel electrophoresis are shown in brackets

manufacturer's instruction. Results of each run were validated with inclusion of appropriate controls as per instructions.

Statistical analysis: Sensitivity was defined as true positive divided by (true positive + false negative) and specificity as true negative divided by (False positive + true negative). Difference in proportions was measured with nonparametric Wilcoxon two sample test (11).

\section{RESULTS}

PCR was performed on 137 specimens from 124 high risk patients. There were 126 blood specimens (118 patients), nine CSF (four patients) and two vitreous fluid (two patients) specimens. Despite the protocol, blood for cultures and PCR were not always collected simultaneously in the study patients. Duplicate blood specimens for PCR (two specimens within $24 \mathrm{~h}$ ) were received from six patients. Two were positive by PCR, and none had a discordant result. Duplicate specimens were counted as one. Seventy-five patients had no evidence of invasive candidal infection. However, Candida species were isolated from multiple sites from 63.

Twenty-five patients had either a positive catheter tip or blood cultures for yeast. The blood of 17 of the 25 patients were positive by PCR (group A). Fifteen were positive by electrophoresis as well as by EIA detection methods. Two patients were positive by only the more sensitive EIA method. PCR failed to detect candidemia in the other eight patients (group B).

Blood specimens from 17 patients with both positive blood cultures (including one catheter tip-positive patient) and PCR (group A) were collected a mean of 0.73 days (range 0 to 3 ) after the last positive blood culture specimen was drawn. Also, two or more blood cultures taken over $48 \mathrm{~h}$ were positive for Candida species from 12 of 17 patients.

Six patients had positive blood cultures and two had positive catheter-tip cultures but negative PCR (group B). In contrast to the results from group A, the PCR specimens from group B were taken a mean of 4.5 days (range 0 to 16 ) following the last positive blood culture specimen. Only two of the eight patients had two or more positive blood cultures for yeast. The number of days between the collection of the last positive blood culture and PCR specimens, and the number of positive cultures were significantly different between groups $A$ and $B(P=0.004$ and $P=0.010$, respectively).

Specimens from 12 patients yielded a positive PCR result but their blood cultures remained negative for yeast (Table 1). Eleven of these patients had more than four risk factors for in- vasive candidiasis, had negative bacterial cultures from significant sites and had received multiple antibiotics without a response. Clinically, the patients were thought possibly to have invasive fungal infection and improved with empirical amphotericin B therapy. Results of PCR were not available to the attending physician at the time of clinical diagnosis or during the therapy of suspected invasive candidiasis.

One of the 11 patients had peritonitis, and subsequently $C$ albicans grew from a peritoneal fluid specimen. In another patient, $C$ albicans was isolated from a vascular graft site specimen which was taken during surgery. Yeast was not isolated from blood or any other sterile site in the remaining nine patients; however a Candida species was isolated from bronchial brushing and bronchial lavage specimens of four patients.

The 12th patient had an appropriate number of risk factors and a positive PCR. He had undergone esophagectomy because of malignancy. His blood cultures remained negative for yeast, but fluid from the surgical wound demonstrated a heavy growth of $C$ albicans as did other mucosal sites. The patient was not considered to have an invasive candidal infection at the time and was not treated. In this patient, both methods of amplicon detection were positive, but the test was considered to be false positive.

Seven patients were culture- and PCR-negative for candida but had more than four risk factors. These patients failed to respond to multiple antibiotics and were thought to have possible invasive candidiasis. All were treated with fluconazole or amphotericin B with success.

Table 1 shows the sensitivity of blood cultures and PCR with positive and negative predictive values for PCR. Calculations are based on the 25 patients whose blood cultures were positive for Candida species, plus the 18 patients with possible invasive candidiasis. The sensitivity of blood culture for the detection of invasive candidal infections was $58.1 \%$ and that of PCR was $60.4 \%$ by gel electrophoresis and $65.1 \%$ by EIA. Only one of the 75 remaining high risk patients had a false positive PCR test, giving a specificity rate of $98.6 \%$, although 63 patients were heavily colonized by candida.

In addition, three patients with meningitis and endophthalmitis tested positive with PCR and culture. Yeast was isolated from the CSF of two patients whose blood cultures and PCR on blood samples were negative. Four CSF specimens obtained over 10 days from one of the patients were all positive by PCR, but only one of these specimens grew $C$ albicans. The 
case is described elsewhere in detail (12). CSF from the second patient was positive by culture as well as by PCR. Vitreous fluid from a patient with endophthalmitis grew $C$ albicans that was also detected by the PCR method. Culture and PCR methods failed to detect yeast in blood collected from this patient.

\section{DISCUSSION}

Invasive candidiasis is now a common infection among immunosuppressed, transplant, hematologic/oncology and intensive care unit patients $(13,14)$. Fungi accounted for about $8 \%$ of all nosocomial infections between 1986 and 1989, and $80 \%$ of these were caused by Candida species (14). During the same period, Candida species were the fourth most common cause of septicemia. Reported mortality among patients with fungemia ranges between $50 \%$ and $80 \%$ despite treatment (15).

The diagnosis of invasive infections due to Candida species remains problematic. Routine blood cultures are relatively insensitive. Depending on the blood culture system used, frequency of sampling and the total volume of blood cultured during an episode, it is estimated that cultures may fail to detect $18 \%$ to $75 \%$ of cases of invasive candidiasis (16). In addition, there may be lapse of two to five days before blood cultures show growth.

A more sensitive and reliable method is desirable for the rapid and accurate diagnosis of invasive infections due to Candida species. PCR holds the promise of detecting a very low number of target molecules and, further, is capable of detecting viable as well as nonviable organisms. Several investigators, therefore, have used PCR for the detection of Candida species (17-20). All prior studies were carried out with nonclinical specimens or examined only a limited number of clinical samples.

Lysis-centrifugation cultures are able to estimate the number of CFUs of an organism present per millilitre of blood. Using this culture technique, Whimbey et al (21) demonstrated that cultures drawn from peripheral veins often only had 0.1 to $0.2 \mathrm{CFU} / \mathrm{mL}$ of Candida species. Telenti and Roberts (1) further confirmed that significant numbers of blood specimens from candidemic patients contain less than $1 \mathrm{CFU} / \mathrm{mL}$. Ideally, any method used in the diagnosis of invasive candidiasis should be able to detect this number of organisms. To achieve this goal we chose to use a large volume $(3 \mathrm{~mL})$ of whole blood and not plasma. High speed centrifugation to pellet the white blood cells and yeast cells with subsequent lysis of cells was used to capture extra- and intracellular organisms. Purified DNA was reconstituted with the smallest possible volume of water. In addition, primers were chosen that target a DNA sequence that is present in multiple copies (30$150)$ in the candidal genome (22). The PCR assay could detect 5 to $10 \mathrm{CFU}$ in $3 \mathrm{~mL}$ spiked blood (data not shown), and this result was not much different from the findings of Holmes et al (9). We could also confirm their observation (9) that the assay is capable of detecting nonalbicans Candida, although the number of such organisms (Candida glabrata 2, Candida parapsilosis 1, and Candida tropicalis 1) detected in the present study was small.
Overall sensitivity of the PCR method in the present study was slightly better, although not significantly so, than blood cultures (65.1\% versus $58.1 \%)$. The PCR method failed to diagnose candidal infection in eight patients who were positive by blood cultures. Many of these patients may have had transient candidemia that cleared before the PCR specimens were collected. The presence of only one positive blood culture in many of these patients lends credence to this argument. In addition, PCR specimens were often collected from patients later than the positive blood culture specimens. Three culture positive, PCR negative patients had their blood drawn for PCR five days or more after the last positive blood culture and in the intervening period had their intravascular catheters removed or changed and received fluconazole or amphotericin $\mathrm{B}$. If these patients are excluded, the sensitivity of PCR method rises to $65.0 \%$ by the gel electrophoresis detection method and $70.0 \%$ by the hybridization method. It is also important to note that the sensitivity of blood cultures is based on multiple specimens being submitted from each patient. However, with the exception of two cases, only one sample from each patient was processed by PCR. Greater sensitivity of the hybridization method over the gel electrophoresis with ethidium bromide staining is not surprising because enhanced sensitivity of the probe and EIA have been demonstrated previously (15).

In the present study, PCR appears to be superior to blood cultures in the diagnosis of invasive candidiasis. However, this finding is not unique, because amplification methods have been shown to be more sensitive than cultures for other infectious diseases (23).

Invasive candidal infections without detectable candidemia are the most difficult to diagnose. Thaler et al (24) reviewed the world literature and found only five patients with positive blood cultures among 60 cases of hepatosplenic candidiasis. In the hospital of Thaler et al (24), only two of eight patients with this condition were candidemic. We did not encounter a case of hepatosplenic candidiasis during this study; nevertheless, it is encouraging that PCR was positive in 11 cases of blood culture-negative patients clinically suspected of having deep-seated candidiasis. From four of these patients, $C$ albicans grew from bronchial lavage, suggesting heavy colonization which has been identified as a risk factor (25). Culture-negative and PCR-positive patients were of interest to the authors and are the subject of further study.

Sixty-three of 75 patients without invasive candidiasis were heavily colonized with yeast. These patients had many of the risk factors, but had no evidence of a candidal infection. All but one patient was negative by PCR, confirming PCR's high degree of specificity. Several patients were bacteremic from a variety of organisms but the PCR tests were negative, further confirming the specificity of the primers.

In summary, we found PCR testing to be less sensitive than culture in candidemic patients. In our opinion, this decreased sensitivity could be largely explained by delayed and less frequent testing. Patients with invasive nonfungemic disease were detected with our PCR assay, which appeared also to distinguish reliably between invasive disease and yeast colonization only. We believe this assay needs to be studied 
prospectively in a high risk population because it has the potential to complement blood cultures and rationalize the use of antifungals in critically ill noncandidemic patients.

ACKNOWLEDGEMENTS: This work was supported by The Physician's Services Incorporation Foundation (R92-42), North York, Ontario and Victoria Hospital Research Development Foundation (RDF-019-92), London, Ontario.

\section{REFERENCES}

1. Telenti A, Roberts GD. Fungal blood cultures. Eur J Clin Microbiol Infect Dis 1989;9:825-31.

2. Wilson ML, Davis TE, Mirrett S, et al. Controlled comparison of the BACTEC high blood volume fungal medium, BACTEC plus 26 aerobic blood culture bottle, and 10-milliliter isolator blood culture system for detection of fungemia and bacteremia. J Clin Microbiol 1993;4:865-71.

3. Lemieux C, St Germain G, Vincelette J, Kaufman L, de Repentigny L. Collaborative evaluation of antigen detection by a commercial latex agglutination test and enzyme immunoassay in the diagnosis of invasive candidiasis. J Clin Microbiol 1990;28:249-53.

4. Wong B, Bauer KL. Enantioselective measurement of fungal $\mathrm{D}$-arabinitol in the serum of normal adults and patients with candidiasis. J Clin Microbiol 1988;26:1670-4.

5. Walsh TJ, Hathorn JW, Sobel JD, et al. Detection of circulating candida enolase by immunoassay in patients with cancer and invasive candidiasis. N Engl J Med 1991;324:1026-31.

6. Isenberg HD. Clinical Microbiology Procedure Handbook. Washington: American Society for Microbiology, 1994;1.1.1-1.17.15.

7. Maki DG, Weise CE, Sarafin HW. A semiquantitative culture method for identifying intravenous catheter-related infection. N Engl J Med 1977;296:1305-9.

8. Sambrook J, Fritsch EF, Maniatis T. Molecular Cloning: A Laboratory Manual, 2nd edn. Cold Spring Harbor: Cold Spring Harbor Laboratory, 1989;E.3-4.

9. Holmes AR, Cannon RD, Shepherd MG, Jenkinson HF. Detection of Candida albicans and other yeasts in blood by PCR. J Clin Microbiol 1994;32:228-31.

10. Bloch W. Wax-mediated hot start PCR: Ampliwax PCR gems permit nonisotopic, unprobed detection of low-copy-number targets. Amplifications 1992;8:6-9.
11. Conover WJ. Practical Nonparametric Statistics, 2nd edn. New York: John Wiley \& Sons, 1980.

12. Ralph ED, Hussain Z. Chronic meningitis caused by Candida albicans in a liver transplant recipient: Usefulness of the polymerase chain reaction for diagnosis and for monitoring treatment. Clin Infect Dis 1996;123:191-2.

13. Bodey GP. The emergence of fungi as major hospital pathogens. J Hosp Infect 1988;11(Suppl A):411-26.

14. Schaberg DR, Culver DH, Gaynes RP. Major trends in microbial etiology of nosocomial infection. Am J Med 1991;191(Suppl 3B):72S-5S.

15. Armstrong D. Problems in management of opportunistic fungal disease. Rev Infect Dis 1989;11(Suppl 7):S1591-9.

16. Jones JM. Laboratory diagnosis of invasive diagnosis. Clin Microbial Rev 1990;13:32-45.

17. Buchanan TG, Rossier M, Merz WG, Charache P. Detection of surgical pathogens by in vitro DNA amplification. Part 1. Rapid identification of Candida albicans by in vitro amplification of a fungus-specific gene. Surgery 1990;108:338-47.

18. Miyakawa Y, Mabuchi T, Kayaga K, Fukazawa Y. Isolation and characterization of a species-specific DNA fragment for detection of Candida albicans by polymerase chain reaction. J Clin Microbiol 1992;30:894-900.

19. Rand K, Houck H. Development and application of polymerase chain reaction for the detection of Candida albicans. 32nd Interscience Conference on Antimicrobial Agents and Chemotherapy, Anaheim, California, October 11-14, 1992. (Abst)

20. Kan VL. Polymerase chain reaction for the diagnosis of candidemia. J Infect Dis 1993;168:779-83.

21. Whimbey E, Wong B, Kiehn TE, Armstrong D. Clinical correlation of serial quantitative blood cultures determined by lysis-centrifugation in patients with persistent septicemia. J Clin Microbiol 1984;19:766-71.

22. Iwaguchi SL, Homma M, Tanaka K. Clonal variation of chromosomes size served from the rDNA cluster region in Candida albicans. J Gen Microbiol 1992;138:1893-900.

23. Ossewaarde JM, Rieffe M, Rozenberg-Arska M, et al. Development and clinical evaluation of a polymerase chain reaction test for detection of Chlamydia trachomatis. J Clin Microbiol 1992;30:2122-8

24. Thaler M, Pastakia B, Shawker TH, O'Leary T, Pizzo PA. Hepatic candidiasis in cancer patients: The evolving picture of the syndrome. Ann Intern Med 1988;48:195-9.

25. Wenzel RP. Nosocomial candidemia: risk factors and attributable mortality. Clin Infect Dis 1995;20:1531-4. 


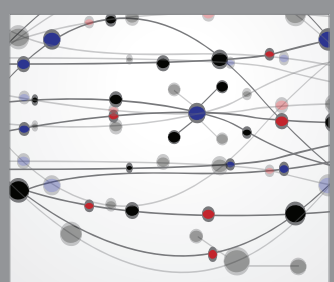

The Scientific World Journal
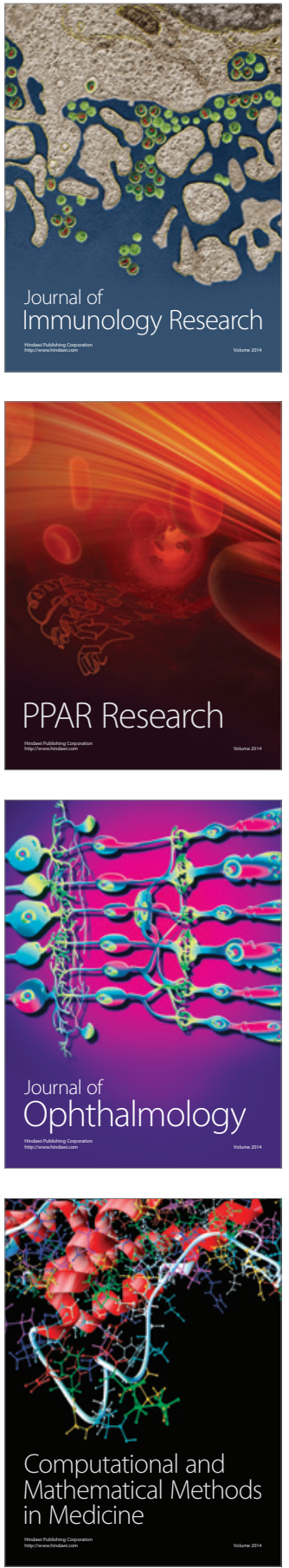

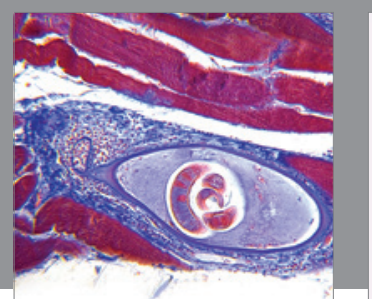

Gastroenterology Research and Practice

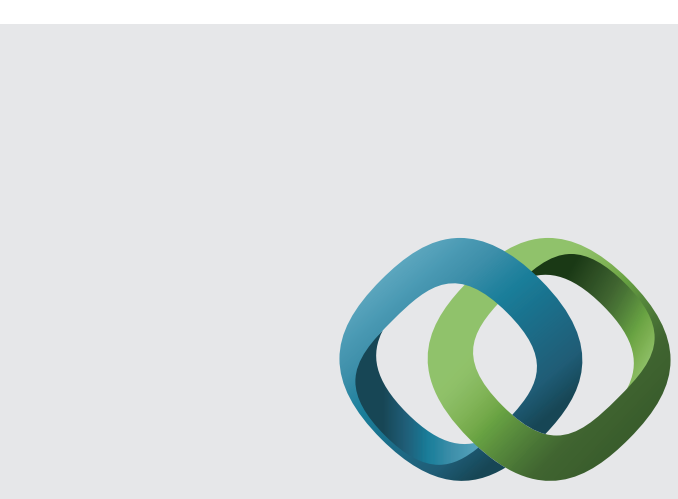

\section{Hindawi}

Submit your manuscripts at

http://www.hindawi.com
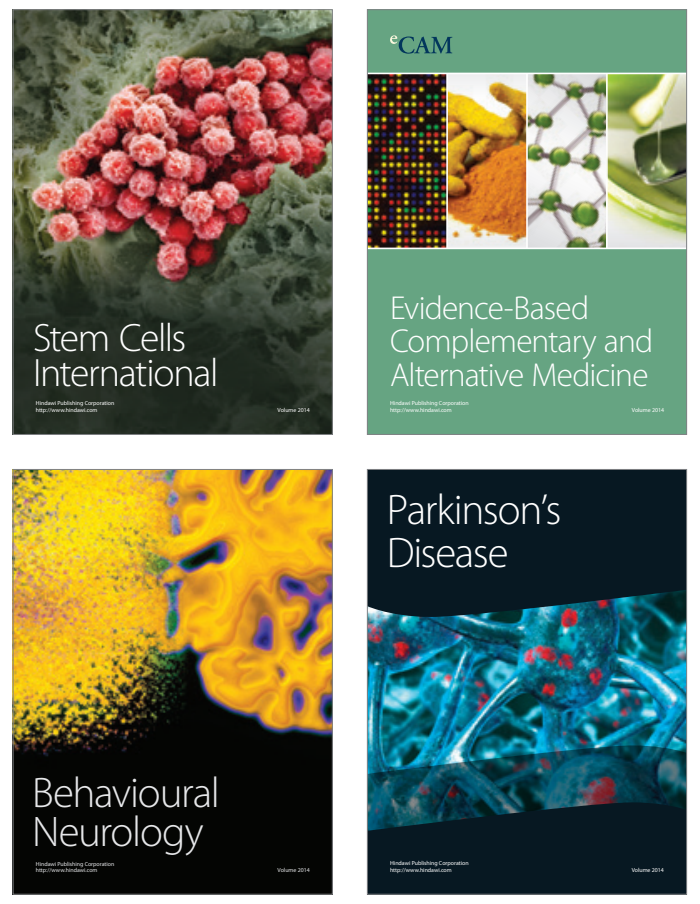
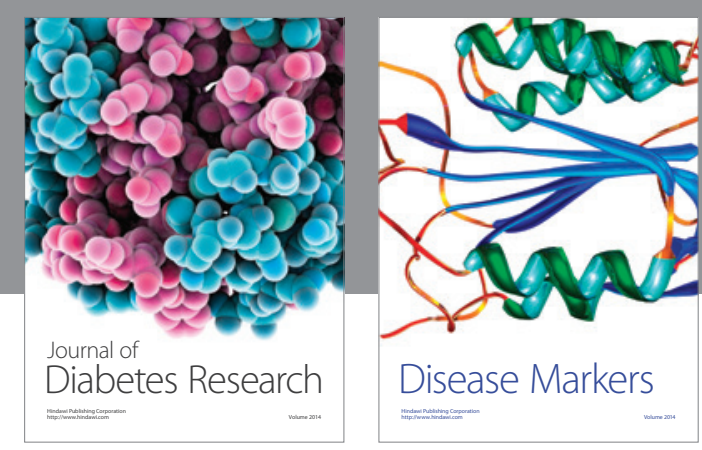

Disease Markers
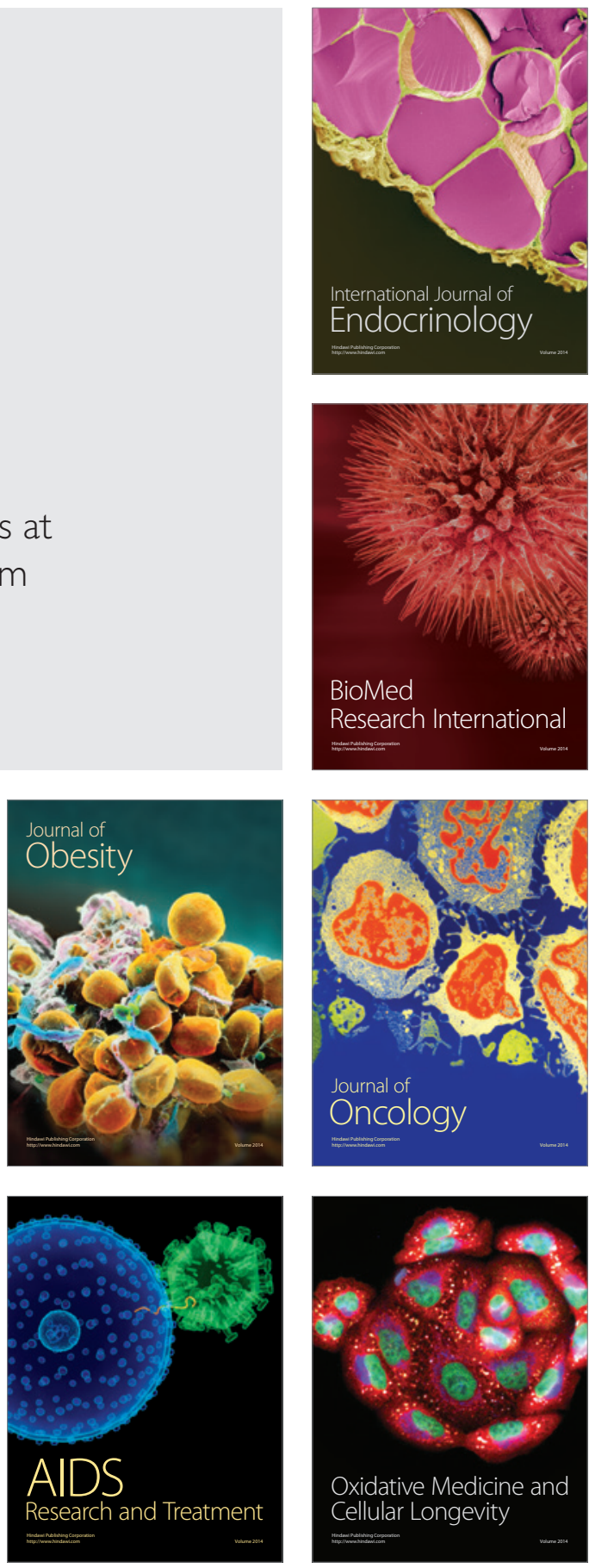